\title{
Analisis Pengukuran Kinerja Sales-Funding Officer dalam Kegiatan Pemasaran Produk Tabungan Haji Mabrur BSM di Bank Syariah Mandiri (BSM) kc Ahmad Yani Kota Bandung melalui metode Balance Scorecard
}

\author{
Divi Ghearizky Kartia Ifa Habifia Senjiati Yayat Rahmat H \\ Program Studi Hukum Ekonomi Syariah, Fakultas Syariah, Universitas Islam Bandung \\ Jl. Tamansari No. 140116 \\ divi.ghearizky@gmail.com, ifa wahyudin@gmail.com, yayatrahmathidayat@unisba.ac.id
}

\begin{abstract}
Abstarct-The performance of sales funding in marketing the BSM Hajj Mabrur Savings product is important to be done as an evaluation material for BSM management in increasing DPK acquisition. Due to the increasing number of DPK from BSM Haji Mabrur Savings products, the opportunity to obtain profits from financing products distributed will also increase. In this case, the measurement of sales funding performance at BSM KC Ahmad Yani is done through the balance scorecard method. Based on these problems, the research is formulated into the following questions: How is the implementation of sales funding performance in marketing BSM Hajj Mabrur Savings products at Bank Syariah Mandiri KCP Ahmad Yani? And how is the performance of Bank Syariah Mandiri KC Ahmad Yani's sales funding measured by the Balanced Scorecard approach? The research method used is descriptive analytical by examining the performance of Bank Syariah Mandiri KC Ahmad Yani sales funding measured by the Balanced Scorecard approach. The results of this study are the implementation of sales funding performance in marketing the BSM Hajj Mabrur Savings product at Bank Syariah Mandiri KCP Ahmad Yani in accordance with the applicable SOP of BSM services. The performance of Bank Syariah Mandiri KC Ahmad Yani's sales funding measured by the Balanced Scorecard approach shows the level of performance of the sales funding team from the perspective of customers and other employees at BSM KC Ahmad Yani each have an average score of $76.2 \%$ and $81.2 \%$ which represent from the customer's perspective with a good category and other employee perspectives are very good.
\end{abstract}

Keywords-Performance, Sales, Savings and Islamic Banks.

Abstraks-Kinerja para sales funding dalam memasarkan produk Tabungan Haji Mabrur BSM penting untuk dilakukan sebagai bahan evaluasi bagi manajemen BSM dalam meningkatkan perolehan DPK. Karena dengan meningkatnya jumlah DPK dari produk Tabungan Haji Mabrur BSM, maka peluang untuk memperoleh laba dari produk pembiayaan yang disalurkan pun akan ikut meningkat. Dalam hal ini, pengukuran kinerja sales funding di BSM KC Ahmad Yani dilakukan melalui metode balance scorecard. Berdasarkan permasalahan tersebut, maka penelitian dirumuska ke dalam bentuk pertanyaan sebagai berikut : Bagaimana pelaksanaan kinerja sales funding dalam memasarkan produk Tabungan
Haji Mabrur BSM di Bank Syariah Mandiri KCP Ahmad Yani ? Dan bagaimana kinerja sales funding Bank Syariah Mandiri KC Ahmad Yani diukur dengan pendekatan Balanced Scorecard ? Metode penelitian yang digunakan adalah deskriptif analitis dengan meneliti kinerja sales funding Bank Syariah Mandiri KC Ahmad Yani diukur dengan pendekatan Balanced Scorecard. Hasil penelitian ini adalah pelaksanaan kinerja sales funding dalam memasarkan produk Tabungan Haji Mabrur BSM di Bank Syariah Mandiri KCP Ahmad Yani telah sesuai dengan SOP pelayanan yang berlaku BSM. Kinerja sales funding Bank Syariah Mandiri KC Ahmad Yani diukur dengan pendekatan Balanced Scorecard menunjukkan tingkat kinerja tim sales funding dari perspektif nasabah dan karyawan lain di BSM KC Ahmad Yani masing-masing memiliki rata-rata skor sebesar $\mathbf{7 6 . 2 \%}$ dan $81.2 \%$ yang merepresentasikan dari perspektif nasabah dengan kategori baik dan peerspektif karyawan lain sangat baik.

Kata Kunci-Kinerja, Sales, Tabungan dan Bank Syariah.

\section{PENDAhUluaN}

\section{A. Latar Belakang Masalah}

Bank Syariah Mandiri (BSM) merupakan salah satu bank Syariah yang memiliki produk tabungan sebagai produk pendanaan bagi sumber Dana Pihak Ketiga (DPK) yang dapat disalurkan ke dalam produk pembiayaan sehingga BSM memperoleh pendapatan laba dari kegiatan perbankan yang dilakukannya. Adapun produk tabungan yang dimiliki meliputi tabungan Berencana, tabungan Simpatik, tabungan Haji Mabrur BSM, tabungan Mabrur dan tabungan Qurban. Dalam penelitian ini, penulis akan memfokuskan pada produk Tabungan Haji Mabrur BSM karena produk tabungan ini bersifat umum tidak memiliki kekhususan alokasi pendanaannya seperti produk tabungan lain serta menggunakan akad Mudharabah Mutlaqah dimana pihak nasabah dapat memperoleh imbalan bagi hasil pada tiap bulannya.

Mengingat pentingnya peran ptoduk funding yang menjadi sumber Dana Pihak ketiga (DPK) di BSM, maka manajemen mencanangkan target tertentu akan pendapatan 
DPK tersebut. Dalam hal ini, pihak BSM berupaya untuk mengoptimalkan peran para Account Officer dan Sales Officer Funding agar perolehan DPK dapat maksimal. Dengan demikian, maka kinerja para karyawan BSM khususnya pada bagian Account Officer dan Sales Officer Funding diharapkan dapat menunjukkan performa maksimal sehingga target perolehan DPK yang dicanangkan manajemen BSM dapat tercapai.

Kinerja (performance) dengan prestasi kerja yaitu proses melalui organisasi untuk mengevaluasi atau menilai prestasi kerja karyawan. Kinerja karyawan merupakan prestasi kerja, untuk perbandingan hasil kerja yang dapat dilihat secara nyata dengan standar kerja yang telah ditetapkan perusahaan. Untuk memperoleh karyawan yang memiliki kinerja baik maka diperlukan penerapan kerja. Terkait hal tersebut, pihak BSM dalam mengoptimalkan peran Account Officer dan Sales Officer Funding dalam memperoleh pencapaian DPK yang sesuai target, memfokuskan para sales funding agar dapat menjual produk Tabungan Haji Mabrur BSM karena beberapa alasan diantaranya karakteristik produk tabungan ini yang memiliki nominal relatif besar untuk satu akaun (satu orang nasabah) dan perolehan dana yang konsisten perbulan masuk ke rekening BSM sehingga akan berimplikasi terhadap konsistensi rasio pendanaan BSM sebagai modal dalam penyaluran pembiayaan.

Terkait hal di atas, maka pengukuran kinerja para sales funding dalam memasarkan produk Tabungan Haji Mabrur BSM penting untuk dilakukan sebagai bahan evaluasi bagi manajemen BSM dalam meningkatkan perolehan DPK. Karena dengan meningkatnya jumlah DPK dari produk Tabungan Haji Mabrur BSM, maka peluang untuk memperoleh laba dari produk pembiayaan yang disalurkan pun akan ikut meningkat. Salah satu metode dalam mengukur kinerja sales funding adalah melalui metode Balanced Scorecard. Metode ini merupakan metode pengukuran kinerja baru yang mengubah pengukuran kinerja secara tradisional. Balanced Scorecard dapat menerjemahkan visi dan strategi ke dalam berbagai tujuan dan ukuran, yang tersusun dalam empat perspektif: finansial, pelanggan, proses bisnis internal serta pembelajaran dan pertumbuhan. Pengukuran kinerja dengan metode Balance Scorecard diharapkan memberikan gambaran yang komprehensif tentang kondisi kinerja para pegawai karena metode ini memiliki beberapa indikator penilaian yang terdiri dari empat perspektif meliputi anggaran, konsumen (nasabah), prospek bisnis dan perspektif pembelajaran atau pertumbuhan.

\section{B. Tujuan Penelitan}

Tujuan penelitian ini untuk memperoleh jawaban dari permasalahan yang telah dirumuskan. Adapun tujuan dalam penelitian ini adalah antara lain :

1. Untuk mengetahui pelaksanaan kinerja sales funding dalam memasarkan produk Tabungan Haji Mabrur BSM di Bank Syariah Mandiri KCP Ahmad Yani.
2. Untuk mengetahui kinerja sales funding Bank Syariah Mandiri KC Ahmad Yani diukur dengan pendekatan Balanced Scorecard

\section{LANDASAN TEORI}

\section{A. Tinjauan Umum Kinerja Karyawan}

Kinerja merupakan konsep yang bersifat universal yang merupakan efektivitas operasional suatu organisasi, bagian organisasi dan bagian karyawannya berdasar standar dan kriteria yang telah ditetapkan sebelumnya, karena organisasi pada dasarnya dijalankan oleh manusia, maka kinerja sesungguhnya merupakan perilaku manusia dalam memainkan peran yang mereka lakukan dalam suatu organisasi untuk memenuhi standar perilaku yang telah ditetapkan agar membuahkan tindakan dan hasil yang diinginkan. ${ }^{1}$

Penilaian kinerja merupakan suatu prestasi yang dicapai oleh seseorang dalam melaksanakan tugas atau pekerjaannya, sesuai dengan standar kriteria yang ditetapkan dalam pekerjaan itu. Penilaian kinerja adalah suatu sistem formal dan terstruktur yang mengukur, menilai, dan mempengaruhi sifat-sifat yang berkaitan dengan pekerjaan, perilaku, dan hasil, termasuk tingkat ketidakhadiran. Fokusnya adalah untuk mengetahui seberapa produktif seorang karyawan dan apakah ia bisa berkinerja sama atau lebih efektif pada masa yang akan datang, sehingga karyawan, organisasi, dan masyarakat semuanya memperoleh manfaat. ${ }^{2}$ Pencapaian tujuan yang telah ditetapkan merupakan salah satu tolak ukur kerja individu. Terdapat tiga kriteria dalam melakukan penilaian kinerja yaitu ${ }^{3}$ :

1. tugas individu.

2. perilaku individu.

3. ciri individu.

Menurut Mondy \& Noe dalam buku Human Rescoure Management mengatakan bahwa ada 7 metode penilaian kinerja yaitu ${ }^{4}$ :

1. Rating Scales

2. Critical Incidents

3. Essay

4. Work standard

5. Ranking

6. Forced distribution

7. Behaviourally Anchored Rating Scales (BARS) 


\section{B. Pengukuran Kinerja dengan Balance Scorecard}

Salah satu metode dalam pengukuran kinerja adalah melalui metode balance scorecard. Konsep Balanced Scorecard telah lama dikembangkan oleh Robert S.Kaplan dan David P.Norton. Konsep Balanced Scorecard ini dikembangkan untuk melengkapi pengukuran kinerja finansial atau dikenal dengan pengukuran kinerja tradisional dan sebagai alat yang cukup penting bagi organisasi perusahaan untuk merefleksikan pemikiran baru dalam era competitiveness dan efektivitas organisasi. Konsep ini memperkenalkan suatu system pengukuran kinerja perusahaan dengan menggunakan kriteria-kriteria tertentu. Kriteria tersebut sebenarnya merupakan penjabaran dari apa yang menjadi misi dan strategi perusahaan dalam jangka panjang.5

Konsep Balanced Scorecard berkembang sejalan dengan perkembangan implementasi konsep tersebut. Balanced Scorecard terdiri dari 2 kata, yaitu Kartu skor (scorecard) dan berimbang (Balanced). Kartu skor (Scorecard) Yaitu kartu yang digunakan untuk mencatat skor hasil kinerja seseorang. Kartu skor juga dapat digunakan untuk merencanakan skor yang hendak diwujudkan oleh personel di masa depan. Melalui kartu skor, skor yang hendak diwujudkan personel di masa depan dibandingkan dengan hasil kinerja sesungguhnya. Hasil perbandingan ini digunakan untuk melakukan evaluasi atas kinerja personel yang bersangkutan. Sedangkan berimbang (balanced) yang menunjukkan bahwa kinerja personel atau karyawan diukur secara seimbang dari dua aspek keuangan dan non keuangan, jangka pendek dan jangka panjang, intern dan ekstern. Oleh karena itu, jika kartu skor personel digunakan untuk merencanakan skor yang hendak diwujudkan di masa depan, personel tersebut harus memperhitungkan keseimbangan antara pencapaian kinerja keuangan dan non keuangan, antara kinerja jangka pendek dan kinerja jangka panjang, serta antara kinerja yang bersifat intern dan kinerja yang bersifat ekstern. 6

Menurut Mulyadi balanced scorecard memiliki karakteristik yang khas dan beberapa keungguluan, yaitu7 :

1. Komprehensif

2. Koheren

3. Terukur

4. Seimbang.

\section{HASIL DAN PEMBAHASAN}

Form Penilaian yang berisi KPI akan disusun dan diusulkan oleh pimpinan Divisi masing-masing. Dan melalui unit penunjang di divisi masing-masing, form tersebut dikirimkan ke CMO untuk kemudian ditetapkan skor standarnya. Setelah itu, Form Penilaian Kinerja tersebut akan dikembalikan ke divisi pengirim, sehingga dapat digunakan untuk mengukur kinerja karyawannya. Berdasarkan skor kinerja tersebut dapat ditentukan Nilai Total dari kinerja masing-masing karyawan. Nilai total dapat dilihat pada tabel berikut ini :

Tabel 1.

SKOR PENILAIAN KINERJA BSM

\begin{tabular}{|c|c|}
\hline Jumlah Nilai Terbobot & Yudisium \\
\hline $460-500$ & Sangat Memuaskan \\
$380-459$ & Memuaskan \\
$280-379$ & Cukup \\
$180-279$ & Kurang \\
$<180$ & Tidak Memuaskan \\
SPBTK/SPT & \\
\hline
\end{tabular}

Sumber : Data Divisi SDM BSM KC Ahmad Yani yang sudah diolah, 2019.

Dengan mempertimbangkan nilai total kinerja karyawan yang dinilai, maka perusahaan akan menetapkan nilai kompensasi kenaikan gaji atau bonus secara periodik bagi karyawan bersangkutan atau kompensasi bisa juga berupa kenaikan jabatan/posisi yang sering dikenal dengan istilah promosi jabatan. Penilaian tahun sebelumnya akan menjadi acuan dalam pemberian kompensasi pada tahun berjalan.

Berdasarkan hasil penelitian dan uraian tabulasi jawaban kuesioner responden di atas, maka dapat diketahui bahwa tingkat kinerja tim sales funding dari perspektif nasabah dan karyawan lain di BSM KC Ahmad Yani masing-masing memiliki rata-rata skor sebesar $76.2 \%$ dan 81.2\% yang merepresentasikan dari perspektif nasabah dengan kategori baik dan peerspektif karyawan lain sangat baik. Hasil dari analisis kedua aspek tersebut memiliki hubungan sebab akibat dan saling berkaitan satu sama lainnya. Kinerja tim sales funding menueut perspektif nasabah dan karyawan yang lain di BSM KC Ahmad Yani pada prinsipnya menunjukkan penilaian aspek pertumbuhan dan pembelajaran pada tahun 2015-2018 menunjukkan keberhasilan BSM KC Ahmad Yani dalam meningkatkan produktifitas karyawan dengan nilai ratarata sebesar sebesar 81,2 yang memiliki kategori sangat setuju.

Pada penilaian kinerja Tim Sales Funding menurut perspektif karyawan lain juga menunjukkan kondisi kinerja BSM KC Ahmad Yani sendiri pada aspek proses bisnis 
internal menghasilkan nilai rata-rata keseluruhan pada rasio keuangan sebesar $1,77 \%$. penilaian ini bertujuan untuk mengembangkan inovasi dengan memperluas struktur jaringan operasional, mendesign produk, efisiensi, efektifitas, serta ketepatan waktu proses atau transaksi yang dilakukan untuk meningkatkan layanan produk tabungan Haji Mabrur pda khususnya.

Penilaian kinerja pada kedua aspek di atas berpengaruh besar pada aspek keuangan. Untuk menilai kemampuan perusahaan dalam menghasilkan profit perusahaan dapat diukur melalui rasio keuangan. Hasil rasio keuangan yang telah di ukur meliputi hasil nilai ratarata pada rasio ROA yang bertujuan untuk mencapai tingkat keuntungan yang optimal sebesar 1,12\%, BOPO sebesar $80,49 \%$ dan rasio FDR sebesar $104,70 \% .{ }^{8}$ Pada penilaian kinerja organisasi secara keseluruhan ini, tahun 2015 hingga 2018 rasio keuangan BSM KC Ahmad Yani memiliki skor 173,08\% dan tahun 2017 mencapai skor 196,71\%. Hal ini menunjukkan BSM KC Ahmad Yani berhasil meningkatkan kinerja perusahaan dengan menggunakan konsep Balanced Scorecard.

Hasil penelitian di atas tersebut sejalan dengan teori yang digunakan sebagai dasar penerapan konsep Balanced Scorecard yang digunakan oleh peneliti yang dikemukakan oleh Robert S. Kaplan dan David P. Norton pada tahun 1992 bahwa konsep balanced scorecard dapat menerjemahkan strategi organisasi yang sudah ada untuk disusun menjadi program-program kerja dengan memetakan menjadi alur sebab-akibat yang bisa lebih mudah untuk dipahami dan memberikan kesempatan kepada organisasi untuk menyeimbangkan pengukuran keuangan mereka dengan pengukuran non keuangan. Kemudian hubungannya dengan penelitian terdahulu yang berkaitan penilaian kinerja dengan menggunakan balanced scorecard ini, yaitu penelitian yang dilakukan oleh Vany Juliarti yang membahas tentang bagaimana pengukuran kinerja PT Bank Rakyat Indonesia (Persero) Tbk. Wilayah Makassar menggunakan perspektif balanced scorecard. Hasil analisis mengenai perspektif keuangan yang dicapai oleh PT Bank Rakyat Indonesia (Persero) Tbk. Wilayah Makassar menunjukkan bahwa kinerja keuangan yang dicapai sudah sesuai dengan standar yang telah ditentukan.

Dari hasil analisis perspektif pelanggan ditinjau dari customer care management, terlihat bahwa PT Bank Rakyat Indonesia sudah dapat mempertahankan pelanggan lama dan selain itu PT Bank Rakyat Indonesia (Persero) Tbk. Wilayah Makassar sudah mampu meningkatkan jumlah pelanggan (nasabah) baru. Namun kepuasan pelanggan (nasabah) dianggap masih rendah. Hasil analisis mengenai perspektif internal bisnis terlihat bahwa kinerja pelayanan dianggap masih rendah, selain itu dilihat dari learning and growth, hal ini ditandai oleh adanya jumlah tim sales funding yang mengikuti pelatihan dan selain itu tim sales funding sudah disiplin dalam penanganan pekerjaan. Hal ini selaras dengan penelitian yang sedang dilakukan oleh peneliti yaitu tentang penilaian kinerja tim sales funding dalam memasarkan produk Tabungan Haji Mabrur di BSM KC Ahmad Yani Kota Bandung melalui pendekatan balanced scorecard.

Hasil analisis mengenai aspek keuangan yang dicapai oleh BSM KC Ahmad Yani dalam mengoptimalkan peran sales funding untuk memasarkan produk Tabungan Haji Mabrur menunjukkan bahwa kinerja keuangan yang dicapai sudah sesuai dengan harapan, dengan kata lain dalam aspek keuangan menunjukkan perkembangan yang bagus setiap tahunnya. Walaupun dalam rasio profitabilitas yang digunakan untuk mengukur kemampuan perusahaan dalam menghasilkan DPK yang tinggi sehingga pembiayaan dapat disalurkan secara optimal serta memperoleh laba dengan baik.

\section{SIMPULAN}

1. Pelaksanaan kinerja sales funding dalam memasarkan produk Tabungan Haji Mabrur BSM di Bank Syariah Mandiri KCP Ahmad Yani telah sesuai dengan SOP pelayanan yang berlaku BSM dan mendapatkan apresiasi dan respon yang positif dari pihak nasabah.

2. Kinerja sales funding Bank Syariah Mandiri KC Ahmad Yani diukur dengan pendekatan Balanced Scorecard menunjukkan tingkat kinerja tim sales funding dari perspektif nasabah dan karyawan lain di BSM KC Ahmad Yani masing-masing memiliki rata-rata skor sebesar $76.2 \%$ dan $81.2 \%$ yang merepresentasikan dari perspektif nasabah dengan kategori baik dan peerspektif karyawan lain sangat baik. Hasil dari analisis ke dua aspek tersebut memiliki hubungan sebab akibat dan saling berkaitan satu sama lainnya. Kinerja tim sales funding menueut perspektif nasabah dan karyawan yang lain di BSM KC Ahmad Yani pada prinsipnya menunjukkan penilaian aspek pertumbuhan dan pembelajaran pada tahun 20152018 menunjukkan keberhasilan BSM KC Ahmad Yani dalam meningkatkan produktifitas karyawan dengan nilai rata-rata sebesar sebesar 81,2 yang memiliki kategori sangat setuju. 


\section{DAFTAR PUSTAKA}

[1] Agus Dharma. Manajemen Personalia. Penerbit Erlangga, Jakarta, 2005.

[2] Agus Dwiyanto, Reformasi Birokrasi Publik di Indonesia. Gadjah Mada University Press, Yogyakarta, 2008.

[3] Hanawijaya, Keunggulan Komparatif Bank Syariah, Suara Merdeka, Semarang, 2008.

[4] Hasibuan, Malayu S.P. Manajemen Sumber Daya Manusia. PT. Bumi Aksara, Jakarta, 2011.

[5] Malayu Hasibuan, Manajemen Sumber Daya Manusia, Bumi Aksara, Jakarta, 2001.

[6] Mangkunegara, A.A. Anwar Prabu. Manajemen Sumber Daya Manusia Perusahaan. Remaja Rosdakarya, Bandung, 2000.

[7] Moekijat. Manajemen Kepegawaian. Mandar Maju, Bandung, 1989.

[8] Mondy, R.W., Noe, R.M., Premeaux, S.R., Human Resource Management (alih Bahasa oleh Iwan Setiawan), Salemba Empat, Jakarta, 2005.

[9] Nitisemito, Alex S. Manajemen Personalia. Edisis Revisi. Dialihbahsakan oleh Ghalia Indonesia. Balai Aksara dan Yudhistira, Jakarta:, 1982.

[10] Nur Indriantoro, Akuntansi, PT Grafindo, Jakarta, 2000.

[11] Rachmany Hasan, Kepemimpinan dan Kinerja, Cetakan Pertama, Yapensi, Jakarta, 2006.

[12] Robert Bacal. Performance Management (alih bahasa : Gunawan), Gramedia Pustaka Utama. Jakarta, 2001.

[13] Samsudin, H. Sadili. Manajemen Sumber Daya Manusia. CV. Pustaka Setia, Bandung, 2009.

[14] Siswanto, bedjo. 1988. Manajemen Tenaga Kerja. Sinar Baru, Bandung, 1988.

[15] Sondang P. Siagian, Manajemen Sumber Daya Manusia, Cetakan ketiga belas, Bumi Aksara, Jakarta, 2006.

[16] Sugiyono. Metode Penelitian Kuantitatif, Kualitatif dan $R \& D$. Alfabeta, Bandung, 2008.

[17] Suryabrata, Sumadi. Metodologi Penelitian. Jakarta, P.T. RajaGrafindo Persada, 1994.

[18] Syahrul Fauzi Siregar, Penilaian Prestasi Kerja, Jurnal Ekonomi No. 26/II/2009 USU, Medan, 2009.

[19] Veitzal Rivai, Manajemen Bank Syariah, Rajawali Press, Jakarta, 2004.

[20] Zainul Arifin, Dasar-Dasar Manajemen Bank Syariah, Cetakan 3, Alvabet, Jakarta. 2005. 